\title{
EL VALOR DEL MUNICIPIO EN LA HISTORIA DE MÉXICO
}

\author{
THE VALUE OF MUNICIPALITY IN THE HISTORY OF MEXICO
}

José Alberto del Rivero-del Rivero ${ }^{1} *$ (D)

1. Universidad Juárez Autónoma de Tabasco, División Académica de Ciencias

Sociales y Humanidades, Villahermosa, Tabasco, México.

*Correspondencia del Autor: José Alberto del Rivero-del Rivero, correo electrónico: josealberto@delriveroasociados.mx

\section{RESUMEN}

Este articulo tiene como objetivo demostrar que la esfera municipal representa la base del federalismo mexicano y que, por ende, debe ser incluida normativamente como tal en el texto fundamental de México. Para dicha comprobación, fue necesario realizar un estudio cualitativo de la normatividad actual bajo la hermenéutica de las fuentes del Derecho (formales, reales e históricas) en relación a este tema, como parte del método de las ciencias jurídicas. Como resultado principal se obtuvo que es necesario realizar una reforma a la constitución mexicana a fin de incluir la esfera municipal dentro del federalismo. Esto sería congruente con el contexto en el que se originó el federalismo mexicano al ser el municipio (como organización territorial) y su ayuntamiento (como estructura de gobierno) entes previos a la transición posterior de las provincias españolas a los actuales estados y de su integración en una federación después de la Independencia de México.

Palabras claves: federalismo; municipio; ayuntamiento; constitución mexicana.

Cómo citar:

del Rivero-del Rivero, José Alberto. (2020). El valor del municipio en la Historia de México. Revista de Investigaciones Universidad del Quindio, 32(1), 71-78. https://doi.org/10.33975/riuq.vol32n1.438 


\begin{abstract}
The main purpose of this article is to demonstrate that the municipality sphere represents the basis of Mexican federalism and, therefore, should be normatively included as such in the Mexican constitution. To verify this, it was necessary to conduct a qualitative study regard the current regulations under hermeneutics applied to the sources of law (formal, real and historical) in relation to this subject, as part of the method of legal sciences. The main result obtained was that it is necessary to amend the Mexican constitution to include the municipal sphere within the federal union. This would be congruent with the context in which Mexican federalism emerged as the municipality (territorial organization) and its council (government structure) are entities prior to the subsequent transition from the Spanish provinces to the current states and its integration into a federation after the Mexican Independence.
\end{abstract}

Keywords: federalism, municipality, municipal council, Mexican Constitution.

\section{INTRODUCCIÓN}

El federalismo mexicano se caracteriza por ser un pacto tripartito entre tres esferas (municipios, estados y federación), al menos esas fueron las intenciones del Congreso Constituyente de 1916 - 1917, pero normativamente se omite en la Constitución Política de los Estados Unidos Mexicanos (CPEUM) mencionar que los municipios también son "entidades federativas" en dicha unión. El valor histórico que tiene la esfera municipal dentro del federalismo mexicano se remonta a los tiempos precortesianos y se moderniza a lo largo del Siglo XVI, de allí que el objetivo de este artículo sea el comprobar que esta fue la primera esfera en la que se funda el federalismo mexicano.

Empero, por una parte, jurídicamente no existe una previsión normativa constitucional que sitúe a la esfera municipal dentro de este pacto, solamente se cuenta con el artículo 115 constitucional sobre el municipio libre, pero este no cumple en su totalidad con las aspiraciones de los constituyentes, principalmente por la falta de claridad en lo que es un ayuntamiento, tal como se estudiará en esta investigación.

Por otro lado, en cuanto al aspecto fáctico, la esfera municipal a lo largo de la historia del México independiente ha sido invadida por los estados y la federación, lo que ha fomentado una impronta institucional y doctrinaria que concibe al federalismo como "órdenes de gobierno" de manera vertical, situando en último lugar a la esfera que se estudia, sin tener en cuenta que el pueblo ejerce primero su soberanía a través de los poderes del municipio que se constituyen en un Ayuntamiento (estructura de gobierno) que rige a un territorio denominado municipio. Por consiguiente, en este artículo se analiza la viabilidad de una reforma constitucional que sea congruente con la génesis social y jurídica en la que surgió el federalismo mexicano, cuyo peldaño inicial fue la esfera municipal.

\section{METODOLOGÍA}

La presente investigación fue producto de un método de naturaleza jurídica basado esencialmente en la hermenéutica de las fuentes del Derecho, aplicada a nuestro objetivo que residió en estudiar la esfera del gobierno municipal y su exclusión del pacto federal en México. Como sabemos, dentro de las denominadas ciencias jurídicas, las fuentes del Derecho son tres: formales, reales/ materiales e históricas, por lo que todo estudio jurídico debe profundizar en cada una de ellas para obtener resultados verificables $y$, por ende, eventualmente discutibles por parte de futuras investigaciones, en sintonía con los cánones clásicos del método científico. 
En esta investigación, primero se acotó normativamente los preceptos constitucionales que se someterían a un análisis cualitativo, axiológico y teleológico, en aras de conocer si su redacción respeta los valores y finalidad para las cuales fueron creadas y si es acorde a las exigencias de la realidad del colectivo que se estudia concretamente.

Para ello se valoraron las fuentes del Derecho anteriormente mencionadas, comenzando con las formales en las que fue necesario identificar sobre todo material documental-legislativo de principios del Siglo XX que permitiera conocer el trasfondo analítico que dio vida a las normas constitucionales analizadas, así como documentos jurisprudenciales que evidenciaran la comprensión judicial sobre las mismas. En relación a las fuentes reales/materiales se consideró el contexto de la normatividad bajo el umbral sociológico en el que se originaron, principalmente los motivos sociales que permitieron su existencia. Respecto de las fuentes históricas, se estudiaron textos oficiales correspondientes a un momento histórico distinto al actual sistema constitucional mexicano (desde documentos de la época virreinal hasta aquellos que surgieron a partir de 1824 ya siendo México independiente), los cuales ayudan a comprender la indefensión en la que se ha encontrado la esfera municipal tanto normativamente como en la práctica.

\section{RESULTADOS}

1. Dentro del texto constitucional mexicano existen omisiones normativas de las que se comprende que en el sistema federal de México solo existen dos esferas: los estados y la federación.

2. La CPEUM contradice las intenciones del Congreso Constituyente de 1916-1917, el cual concibió al federalismo en tres esferas constitucionales, y en concreto al ayuntamiento lo visualizó con sus tres poderes propiamente.

3. Históricamente tanto el Municipio (territorio) como el Ayuntamiento (estructura de gobierno) constituyen la primera esfera constitucio- nal en México, precediendo en tiempo a los estados y la federación.

4. Durante la Historia del México independiente, la esfera municipal ha sido fáctica y jurídicamente menguada en la soberanía que el pueblo ejerce a través de su gobierno, evidenciándose a través de los actos invasivos competenciales de autoridades y la falta que tuvieron los gobiernos municipales durante casi un siglo de un mecanismo de defensa constitucional para impugnar dichos actos.

5. La noción política y académica de "órdenes de gobierno" es incorrecta, ya que hace suponer que existe una prelación de una esfera frente a las demás.

Figura 1. Visión decimonónica vertical del federalismo basada en órdenes de gobierno

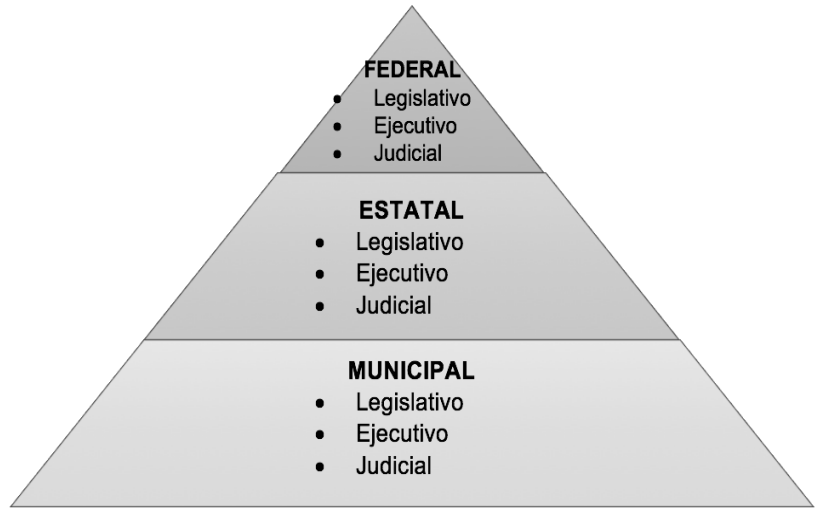

1. La expresión que debe usarse dentro de la concepción del federalismo mexicano es "esferas constitucionales", puesto que, en lugar de establecer un orden vertical de poder, supone una concatenación, donde cada esfera es autónoma entre sí, pero enlazada de manera horizontal en una gobernanza.

Figura 2. Visión horizontal del federalismo basado en esferas constitucionales

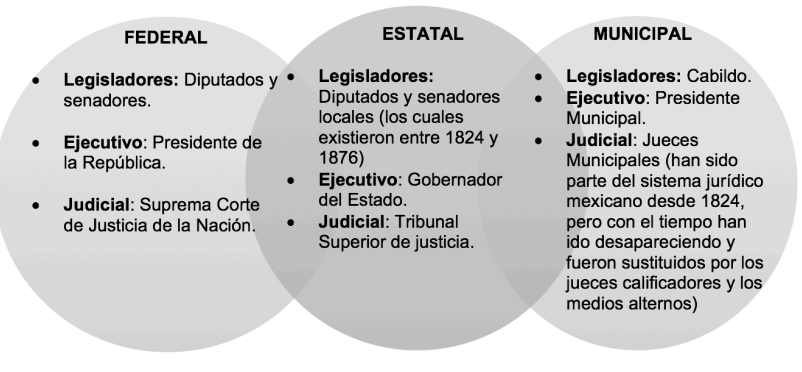




\section{DISCUSIÓN}

El federalismo es una forma de Estado que se caracteriza por la unión política pactada entre diferentes entes territoriales que conservan sus propios gobiernos, originando la coexistencia de más de una esfera de poder. Usualmente son dos esferas, a saber: los gobiernos estatales y el federal, como es el caso de los Estados Unidos (EE.UU.), en donde se originó este sistema. Cabe esclarecer que la Constitución de los EE.UU. no hace referencia a los municipios como parte integrante de la Unión, corresponde a la legislación de cada Estado su organización territorial interna, bajo la denominación de "condados", excepto Luisiana en donde se tiene la institución de "parroquias" (Quintana Roldán, 2008). No obstante, hay países en los que se incluye constitucionalmente al municipio como una tercera esfera.

En el caso de México, la previsión normativa del federalismo se encuentra regulada fundamentalmente en los artículos 40 y 41 de la CPEUM (Congreso de la Unión, 2021), pero lamentablemente se comprende que en el pacto federal solo coexisten dos esferas, la de los estados y de la federación. Es decir, se omite mencionar al gobierno municipal. La anterior situación es incongruente con las aspiraciones de los diputados que integraron el Congreso Constituyente durante los años de 1916 y 1917. En específico, se destacan las palabras del diputado constituyente, Humberto Jara (1917), de las que se entiende que el municipio forma parte de este pacto federal y que como tal cuenta con sus tres poderes al igual que las otras esferas:

(...) el pacto federal lo entiendo a base de un respeto mutuo, a base de una verdadera concordia y no a base de invasión a la soberanía. Hemos venido luchando por conseguir la soberanía, arrancando desde los municipios; de allí es que con todo entusiasmo, más bien con ardor, hemos aceptado el proyecto del Primer Jefe en lo que atañe a este punto. ¿Por qué? Porque al Municipio lo consideramos como la base de nuestras instituciones, porque son los pequeños organismos que forman el gran conjunto; oja- lá, señores, que a los municipios, que también en pequeño tienen sus tres poderes y también en pequeño tienen su Poder Legislativo en el Cabildo, su Poder Ejecutivo en el presidente municipal y el Poder Judicial en los jueces, se les tenga el mismo respeto que ahora se tributa a los Estados de la Federación. Entonces habremos conseguido nuestro ideal, entonces habremos establecido una verdadera libertad, una verdadera soberanía. (citado en Comisión Nacional para la Celebración del Sesquicentenario de la Proclamación de la Independencia Nacional y del Cincuentenario de la Revolución Mexicana, 1960, p. 809).

A esta valiosa disquisición, se aúna el análisis de otro diputado constituyente, Pastrana Jaimes (1917), de quien se comprende que la esfera municipal antecede en tiempo a la de los estados y la federación:

Primeramente, la soberanía se ejercita por la autoridad municipal; después, por las de los Estados, y en último lugar, por las autoridades de la Republica. (...) En los ayuntamientos encontramos los gérmenes de todos los poderes; el germen del Poder Judicial, el germen del Poder Ejecutivo y el germen del Poder Legislativo. El ayuntamiento es un Poder, se quiera o no se quiera. Que el ayuntamiento no pueda dictar leyes, es una mentira. (citado en Comisión Nacional para la Celebración del Sesquicentenario de la Proclamación de la Independencia Nacional y del Cincuentenario de la Revolución Mexicana, 1960, pp. 164 y 165).

Desprendiéndose de lo anterior, es menester comprender que el gobierno municipal reside en un ayuntamiento, y que este no solo corresponde al poder ejecutivo de los municipios, sino que a él concurren el legislativo (cabildo) y el judicial (jueces municipales de paz que actualmente ya no existen y fueron sustituidos por jueces calificadores). Indebidamente se utiliza la expresión "gobierno" como sinónimo del ejecutivo, pero de acuerdo con Burgoa (2003, p. 207) esto se debe a una "corruptela tradicional e histórica".

Como contrapartida a las omisiones constitucio- 
nales en México, hay ejemplos de otros países, como Brasil cuya constitución señala en su artículo 1: "La República Federativa de Brasil, formada por la unión indisoluble de los estados y municipios y del Distrito Federal, se constituye en un Estado Democrático de Derecho..." y el artículo 18 "La organización político-administrativa de la República Federativa de Brasil comprende la Unión, los Estados, el Distrito Federal y los Municipios, todos autónomos en los términos de esta Constitución" (Traducción propia de Câmara dos Deputados do Brasil, 2020).

Resulta ser una gravedad que, a pesar de que históricamente el municipio y su estructura de gobierno ha sido la génesis del federalismo mexicano, nuestro texto fundamental lo excluya como parte integrante de este pacto. En relación a ello, debe recordarse que los orígenes del municipio en México, como entidad territorial, se remontan a antes del arribo de los conquistadores, pues ya existía la esencia de producción del municipio rural bajo la denominación de calpulli o chinancalli, institución que con el paso del tiempo y la influencia española cambió de nombre, pero en teoría fueron respetados por la corona española, así como también lo fue el matrimonio entre naturales y españoles (Levene, 1973). Las intenciones de la corona se comprueban con la Real Cédula de 1560 de Felipe II (Sotelo Inclán, 1943) y que más tarde apostilló con sus ordenanzas de 1573 en donde se abogaba por una supuesta pacificación y población de los territorios sin despojar a los naturales (Fernández Sotelo, 1987), que al final fue todo lo contrario. Aun así, dichos documentos más tarde legitimarían los reclamos de tierras como parte fundamental de los municipios de la población liderada por Emiliano Zapata durante la Revolución Mexicana, como consecuencia de los abusos cometidos por el acaparamiento de tierras a partir de 1824 .

También es imprescindible mencionar otro hecho que demuestra cuál fue la primera esfera del federalismo mexicano. Para ello, será necesario retomar el proceso de llegada de Hernán Cortés a México, en razón de que para justificar su expedi- ción precisaba de legitimación democrática. Esto pudo lograrlo fundando en 1519 el municipio de Villa Rica de la Vera Cruz, situación que provocó un surgimiento de ciudadanos, ya no de Cuba, sino de este nuevo municipio, precisando ahora una estructura para gobernarse, por lo que primeramente se integró un cabildo que de manera inmediata elegiría a Cortés como capitán general y oficial de justicia (justicia mayor) (Díaz del Castillo, 1986; Madariaga, 1970; Duverger, 2019; Quintana Roldán, 2008). En otras palabras, este fue el antecedente inmediato del primer ayuntamiento en México, con funciones (si acaso en ese momento rudimentarias por la falta de separación de poderes) legislativas en el cabildo, así como ejecutivas y judiciales en la persona de Cortés.

Por lo que respecta a la esfera constitucional de los estados y de la federación (segunda y tercera esfera), ambas surgirían oficialmente después de la consecución de la Independencia dado que la federalización en México fue de carácter centrífugo (de adentro hacia fuera), contrario sensu al caso estadounidense que fue centrípeto (de afuera hacia dentro), porque ya existían estados que eran autónomos, pero pactaron integrarse en una federación (Sánchez de la Barquera y Arroyo, 2014). Por lo que respecta a México, los estados fueron creados desde los albores del Siglo XIX hasta las postrimerías del Siglo XX. En cuanto a ello, se debe recapitular que la adopción del federalismo en el sistema político mexicano, de acuerdo con Rabasa (1997, p. 29), se suprimió el absolutismo y se logró "otorgar a las antiguas provincias de la Nueva España, cuya penuria había sido más por el abandono que por una denominación efectiva, los mismos principios de autosuficiencia política que se otorgaban al gobierno federal..." Un ejemplo de ello es el estado de Tabasco, que fue concebido constitucionalmente como estado hasta 1824, ya que antes era parte de la Intendencia de Yucatán (Barceló y Piña, 2010). En este punto es crucial aclarar que el estado de Tabasco fue reconocido como tal gracias al impulso de Eduardo Cárdenas, quien abogó ante las Cortes de Cádiz de 1812 por la autonomía de Tabasco, y precisamente fue elegido diputado representante por el ayuntamiento de Villahermosa (Gurria Lacroix, 
1979). Esto comprueba una vez más que la estructura de gobierno municipal fue previa a la esfera constitucional de los estados en México, siendo la primera expresión de la voluntad del pueblo.

A pesar de que la esfera constitucional fue concebida de manera previa a la de los estados y la federación desde los inicios del Siglo XVI, no fue sino hasta comienzos del Siglo XX que la expresión "municipio libre" fue incluida en un texto constitucional de corte federal, refiriéndonos a la CPEUM de 1917. Sobre todo porque esta esfera estaba supeditada a otras, como el caso de la jefatura política o los gobiernos estatales y la federación, que en efecto, fue uno de los motivos que originó la Revolución Mexicana. No obstante, como se inició la discusión de este apartado, en la CPEUM no se menciona expresamente que la esfera municipal forme parte de las "entidades federativas", asunto que queda totalmente esclarecido en el artículo 43, pues se especifica que los estados pormenorizados, así como la Ciudad de México, son parte de la federación, pero se omite mencionar que también los municipios lo son, como se desprende de las intenciones del Congreso Constituyente de 1916-1917, anteriormente citadas.

Esta situación ha conllevado a que en la práctica la esfera municipal haya sido menguada a pesar de la existencia del artículo 115 constitucional desde 1917. Resulta también preocupante la redacción de dicha disposición, puesto que no basta con señalar que el municipio libre es la base de la división territorial y de la organización política y administrativa de los estados. Es algo totalmente distinto a mencionar que el pueblo ejercerá su soberanía a través de los poderes municipales y que forma parte del pacto federal, lo cual no existe en nuestra constitución.

Se pueden mencionar algunos ejemplos fácticos de cómo se ha conculcado la esfera municipal a través de la historia del México independiente. El primero de ellos fue cuando el expresidente Álvaro Obregón presentó una iniciativa ante el
Congreso de la Unión para desaparecer a las municipalidades del otrora Distrito Federal, esto con la intención de poder reelegirse en el cargo, de manera tal que ahora sería el titular del ejecutivo federal quien designaría a las autoridades de la capital mexicana, disposición constitucional que fue abrogada. Otro ejemplo es el hecho de que la esfera municipal no contaba con la facultad constitucional para promover controversias constitucionales en México (que es un mecanismo de control de la constitucionalidad a efecto de evitar la invasión de esferas competenciales), contrario a ello, los estados y la federación sí podían hacerlo, situación que colocó al gobierno municipal en una indefensión total de cara a actos invasivos de otras esferas por casi un siglo. Fue hasta principios de la década de los noventa cuando la Suprema Corte de Justicia de la Nación de México resolvió el célebre "amparo Mexicali", en el que determinó que el municipio tenía poder político, puesto que ejerce funciones ejecutivas, legislativas y judiciales, trayendo como consecuencia posteriormente la consignación constitucional para que el municipio pudiese promover controversias constitucionales (Valencia Carmona, 2012). Al respecto, ya Castorena (1926) desde comienzos del siglo pasado advertía que el artículo 41 constitucional no reconocía expresamente que la esfera municipal contase con "poder político", como sí sucedía con los estados y la federación.

Sin lugar a dudas, las omisiones constitucionales de no incluir al municipio como una entidad federativa, aunadas a la subyugación que esta esfera ha padecido en la práctica por parte de los estados y la federación, ha ocasionado que una impronta política y académica contraria a la autonomía de la esfera municipal. Esto en razón de que el federalismo mexicano se visiona bajo una óptica vertical y jerarquizada, en la que el gobierno municipal es relegado en el último puesto. Dicha visión ha fortalecido la postergación de violaciones a la esfera municipal en nuestro país.

Por consiguiente, es fundamental realizar una reforma constitucional específicamente a los ar- 
tículos 40, 41 y 43 de la CPEUM que permita incluir a los municipios como entidades federativas. Sobre este tema, Ortega (2001) ha enfatizado la importancia de establecer que el pueblo ejerce su soberanía también por conducto de los poderes municipales, no solamente a través de los poderes de los estados o de la federación. En adición, el análisis de Muñoz Ledo (2019) es oportuno al concluir que la soberanía original se encuentra en el municipio dado que es la primera expresión del voto popular, motivo por el que debe invertirse la pirámide del federalismo (recordemos el ejemplo histórico de los votos que legitimaron la conquista de Hernán Cortés). A ello se agrega, la premura de que el artículo 115 constitucional establezca que el ayuntamiento en el ejercicio de sus funciones se dividirá en legislativo, ejecutivo y judicial, especialmente para crear pesos y contrapesos en la esfera municipal y la normatividad no se vea cambiada cada tres años con la llegada de un nuevo titular del ejecutivo. Así pues, es necesario que, en lugar de una visión vertical del federalismo, se adopte una óptica horizontal, en donde las tres esferas sean autónomas, pero concatenadas entre sí por la unión de un verdadero pacto federal, otorgando a la esfera municipal el lugar que, como demuestra la historia, se merece.

\section{REFERENCIAS}

1. Quintana Roldan, C. F. (2008). Derecho Municipal. México: Porrúa.

2. Congreso de la Unión. (2021). Constitución Política de los Estados Unidos Mexicanos. México: Cámara de diputados del H. Congreso de la Unión.

3. Comisión Nacional para la Celebración del Sesquicentenario de la Proclamación de la Independencia Nacional y del Cincuentenario de la Revolución Mexicana. (1960). Diario de los Debates del Congreso Constituyente 1916-1917. Tomo II. México: Talleres Gráficos de la Nación.

4. Burgoa, I. (2003). Diccionario de Derecho Constitucional, Garantías y Amparo, $7^{\mathrm{ma}}$ ed. México: Porrúa.

5. Câmara dos Deputados do Brasil (2020). "Constituição da República Federativa do Brasil”. C $\hat{a}$ mara Dos Deputados do Brasil. Recuperado de https://www2.camara.leg.br/atividade-legislati$\mathrm{va} /$ legislacao/constituicao1988

6. Levene, R. (1973). Las indias no eran colonias. Madrid: Espasa-Calpe.

7. Sotelo Inclán, J. (1943). Raiz y Razón de Zapata. México: Etnos.

8. Fernández Sotelo, R. D. (1987). "Mito y realidad en las leyes de población de Indias", en F. de Icaza Defour (coord.), Recopilación de leyes de los reinos de las Indias. 209-313. México: Miguel Ángel Porrúa.

9. Díaz del Castillo, B. (1986). La verdadera Historia de la Conquista de Nueva España; Colección Sepan Cuantos No.5. México: Porrúa.

10. Madariaga, S. (1970). Biografia de Hernán Cortés. México: Porrúa.

11. Duverger, C. (2019). Vida de Hernán Cortés. La espada. (traducción de E. Cazenave, y C. Duverger), México: Taurus.

12. Sánchez de la Barquera y Arroyo, H. (2014). "El federalismo como forma de organización del Estado", en H. Sánchez de la Barquera y Arroyo (ed.), Antologías para el estudio y la enseñanza de la ciencia política. Volumen I: Fundamentos, teoría e ideas políticas (pp. 211-238). México: UNAM.

13. Rabasa, E. O. (1997). Historia de las Constituciones Mexicanas. México: UNAM.

14. Barceló, D. A., y Piña, J.A. (2010). Historia de las Instituciones Jurídicas. Tabasco: UNAM.

15. Gurria Lacroix, J. (1979). "José Eduardo de Cárdenas 1765-1821", En J. E. De Cárdenas. Memoria a favor de La Provincia de Tabasco. (p. 11). México: Consejo Editorial del Gobierno del Estado de Tabasco.

16. Valencia Carmona, S. 2012). "Comentario al Artículo 115”, en M. Carbonell (coord.), Derechos del Pueblo Mexicano; México a través de sus Constituciones Tomo V (pp. 925-1055). México: H. Cámara de Diputados LXI legislatura; Senado de la Republica; SCJN; TEPJF; IFE; IIJ-UNAM; Porrúa.

17. Castorena, J. J. (1926). El problema Municipal Mexicano. México: Editorial Cultura. 
18. Ortega, J. (2001). "Hacia un nuevo federalismo", en D. Valadés, y R. Gutiérrez Rivas (coords.), Economía y Constitución; Memoria del IV Congreso Nacional de Derecho Constitucional Tomo IV (pp. 191-196). México: UNAM.

19. Muñoz Ledo, P. (2019). "Iniciativa para revertir la pirámide invertida del federalismo", en Cámara de Diputados del H. Congreso de la Unión (presidencia), Sesión de la Comisión Permanente del Congreso de la Unión. Sesión llevada a cabo en el Palacio Legislativo de San Lázaro, México. Recuperado de https://youtu.be/Cy5GLVFPpZ8 